\title{
PROFESSOR NATIVO: ISSO AJUDA NO APRENDIZADO DE INGLÊS COMO L2 PARA BRASILEIROS?
}

\author{
Native teacher: Does it help in English learning as L2 for Brazilians?
}

Rosemeyre Moraes de OLIVEIRA Pontifícia Universidade Católica de São Paulo (PUC-SP), São Paulo, Brasil

\begin{abstract}
RESUMO: Neste artigo, o objetivo é identificar se cinco brasileiros que estudaram inglês no exterior (EUA e Inglaterra) com falantes nativos consideram que o aprendizado com um nativo inglês/americano é melhor apenas pela natividade do professor. A partir das comparações das razões delineadas pelos sujeitos poder-se-á concluir se o mito do "falante nativo como melhor professor de inglês para estudantes brasileiros" será confirmado ou refutado.
\end{abstract}

Palavras chave: professor nativo, segunda língua, aprendizado.

ABSTRACT: In this paper, the aim is to identify whether five Brazilian who studied English abroad (USA and England) with native speakers consider that learning with a native English / American teacher is better only by the teacher's nativity. From the comparisons of the reasons outlined by the subjects it will be possible to conclude that the myth of the "native speaker as the best English teacher to Brazilian students" as the best English teacher will be confirmed or refuted.

Key-words: Native teacher, second language, learning. 


\section{Quem Fala Inglês Hoje e Por Quê?}

Com tantos cursos de inglês eficientes no Brasil, por que alguns brasileiros vão ao exterior para estudar com professores nativos? Esta foi a inquietação que norteou a presente pesquisa. Ao optar por um curso de língua inglesa no exterior, o estudante já prevê o contato com falantes nativos e compreensão de novas culturas. Após o contato por imersão, qual a impressão dos brasileiros sobre o falante nativo ser ou não o melhor professor de inglês apenas por esse detalhe? Neste estudo de caso foram delineados por meio de entrevista os aspectos relevantes da aprendizagem de inglês com falantes nativos nos Estados Unidos e Inglaterra por cinco brasileiros que viajaram para esses países a fim de fazer um curso intensivo desse idioma.

Mas por que aprender inglês? Segundo Rajagopalan já ocorreu "a invasão da língua inglesa (LI) na vida de todos os seis bilhões - sem exceção - de seres humanos que habitam o planeta" (RAJAGOPALAN, 2005, p. 135) e se essa invasão não é completa, pelo menos "perto de 1,5 bilhão de pessoas no mundo já possui algum conhecimento da LI e/ou se encontra na situação de lidar com ela no seu dia-a-dia" (RAJAGOPALAN, 2005 p. 149).

Deste modo é inimaginável o mundo moderno e globalizado sem a presença da língua inglesa em termos diversos (como deletar, restartar, feedback, entre outros), livros, manuais de produtos e aparelhos, na música, na maioria dos filmes e nas diversas novelas brasileiras exportadas, assim, de acordo com Pennycook "É nesse sentido que o mundo é inglês" (PENNYCOOK, 1995, p. 52). Segundo Rajagopalan "Há setores na sociedade em que o recurso do inglês se tornou uma necessidade, ou seja, quem se recusa a adquirir um conhecimento mínimo da língua inglesa corre o risco de perder o bonde da história" (RAJAGOPALAN, 2005 p. 149). Fato é que muitos brasileiros viajam ao exterior para aprender a LI, já que consideram que no ambiente natural em que a língua é falada e com professores nativos, o aprendizado será mais fácil. Assim, além de embarcarem no bonde da história, no pacote ainda vem o contato com a cultura local.

A questão principal a ser respondida na análise do corpus é se as avaliações dos brasileiros pesquisados quanto ao "aprendizado de inglês com falantes nativos" correspondem ao mito de "falante nativo ser melhor professor" ou se refutam esse mito.

\section{Conceito de Falante Nativo}

A noção de falante nativo que permeia a Linguística e o ensino de línguas colocam-no como um ser que, a partir do fato de ter nascido no país de origem dessa língua que se pretende aprender (e muitas vezes só por ele), possui pleno domínio dessa língua e viria a ser modelo de professor devido a esse suposto domínio. Assim, cria-se o 
mito de que o falante nativo é o ser cuja competência linguística ultrapassaria os limites do contextual, ou seja, ele é competente para se comunicar em todas as situações mesmo que nunca as tenha vivido. Este é um estereótipo formado pela maioria dos interessados em aprender inglês com um "falante nativo".

Quem é o falante nativo, o ser estereotipado nos anúncios como sendo a excelência e referência no ensino de língua inglesa? Por meio das leituras de Davies (1991, 2003) podemos elencar um conjunto de condições cuja somatória caracterizaria um falante nativo e mostra o que realmente ocorre com os nativos de LI em relação a tais condições.

1) $\mathrm{O}$ falante nativo adquire a língua materna na infância.

2) Todos nós somos então falantes nativos a partir do momento que aprendemos a nos comunicar a partir de nosso próprio código.

3) O falante nativo tem intuições (em termos de aceitação e produtividade) sobre sua gramática idioletal.

4) Todos aceitamos e aderimos tanto às normas da língua padrão quanto da informal, que pode ser um dialeto ou alguma forma linguageira codificada. Entre a linguagem padrão e a informal ocorre uma flexibilidade na qual as variações são aceitas e toleradas, ocorre também o cuidado para que o informal não provoque conflitos políticos ou religiosos, por exemplo. O autor cita como exemplo de inglês informal o que se fala em Cingapura.

5) O falante nativo tem intuições sobre as características da gramática da linguagem padrão que são distintas de gramática idioletal ${ }^{1}$.

6) O autor desmitifica tal afirmação ao dizer que o conhecimento da gramática é adquirido socialmente e nos bancos escolares, a boa comunicação é fator de ascensão social e o contrário ocorre na mesma proporção. Davies cita também que muitos problemas de estudantes são interpretados como de cognição, mas, na realidade, a falta de conhecimento do léxico usado pelo professor muitas vezes isola esse aluno que, acostumado a sua língua informal, acaba por não entender o que o professor diz e tenta ensinar. É uma questão social.

7) O falante nativo tem uma capacidade única de produzir discurso espontâneo e fluente, em ambos a produção e compreensão da língua materna apresenta uma ampla gama de competência comunicativa, que é a "capacidade de mobilizar e articular conhecimentos de língua e de mundo em comunicação, sob certas atitudes, em interação, com o propósito de se situar socialmente numa língua (SOUTO \& ALMEIDA, 2009 P. 6)

8) Tanto a gramática formal quanto a informal não são construídas na mente da criança, elas são fruto da vivência da criança em suas relações (sociais, escolares,

${ }^{1}$ Variantes da língua própria de um indivíduo. 
de trabalho), o que muda é a capacidade de discernir qual(is) das duas gramáticas usar em qual(is) ambientes, essa é de fato a competência comunicativa.

9) O falante nativo tem a capacidade única de escrever de forma criativa (e isso inclui, é claro, a literatura em todos os níveis).

10) Para desmitificar tal afirmação o autor recorre ao conceito da Gramática Universal (intuitiva) que subjaz à Gramática da L1 desse falante: intuitivamente um sujeito não chegaria na confeitaria a dizer "pão um dá queijo de? " porque conhece a ordem canônica dos termos da oração que, em português, é composta de sujeito + verbo + complementos e permite a qualquer pessoa que não tenha escolaridade mínima dizer “(você) dá um pão de queijo (para mim)?”, entretanto, aquilo que é intuitivo não virá a ser erudito, não há de se esperar que o menos escolarizado seja capaz de compor um romance em versos dodecassílabos em todos os 42 cantos.

11) "O falante nativo tem uma capacidade única de interpretar e traduzir para a língua materna da qual é um falante."

Por essas condições, o nível linguístico ${ }^{2}$ de "falante nativo" só será alcançado quando do conhecimento e domínio da L1 e L2, portanto, a capacidade e as ações de tradução e interpretações são possíveis a todos que se dedicarem a aprender, nativo ou não.

De igual modo, as diferenças de opinião sobre o falante nativo surgem devido às formas diferentes pelas quais o conceito é interpretado. "É por isso que tem sido referido como o mito e realidade" (DAVIES, 2004, p.477). Alguns veem o nativo como repositório e guardião da verdadeira linguagem do ponto de vista linguístico; outros, apontam para o nativo como um mecanismo das normalizações da língua. Segundo Davies

\begin{abstract}
"Os dois pontos de vista são relacionados e se fundem em outro, mas o que eles refletem é que as posições diferentes podem ser tomadas com base no interesse e preocupação para o mesmo fenômeno, porque o que está em questão é o falante individual em relação a seu grupo social, bem como as suas normas da comunidade, ou seja, a linguagem padrão" (DAVIES, 2003).
\end{abstract}

A partir do domínio da linguagem padrão, apenas nascer em um local e adquirir socialmente a linguagem ali falada não prepara qualquer pessoa para ser professor, seja ele nativo ou não, ensine ele idiomas ou não. É Rajagopalan (1997) que aponta o mito da

\footnotetext{
${ }^{2}$ Conhecimento de léxico, gramática, fluência, clareza verbal e habilidade para expressar-se nos meios formal e informal.
} 
natividade do falante sendo trazido às discussões pela Linguística Moderna. Em suas palavras

\begin{abstract}
"Como todos os outros mitos, a natividade não é uma crença isolada ou única, mas está relacionada e mutuamente sustentada por outras crenças menores que tipicamente não são interrogadas dentro dos limites das disciplinas. De maneira simplificada, o mito se constitui na crença da existência de um falante nativo, que é alguém que sabe a língua e a conhece perfeitamente bem - e é quem pode, por isso, ser invocado como autoridade suprema e árbitro em matéria de julgamento sobre gramática, etc. Mas esse nativo é somente a ponta visível de um gigante iceberg metafísico. " (RAJAGOPALAN, 1997, p. 226)
\end{abstract}

Rajagopalan postula que o falante nativo de uma língua tem conhecimento dela em proporções maiores e inalcançáveis que qualquer não nativo. Temos então a confirmação de que o nativo é o único falante daquela língua, por excelência. $O$ falante nativo, ideal, estaria imerso, pois numa sociedade ideal que, segundo o autor (1997) seria “o paraíso na Terra”, tal afirmação tem caráter excludente e pejorativo ao não nativo, tal qual a denominação de "bárbaros", dado aos que não eram romanos nascidos e, por isso, não falavam Latim.

Assim, o nativo tem domínio sobre o não nativo, que por sua vez, é relegado ao plano de não ser digno, de não pertencer aos grupos por onde os nativos circulam, enquanto a sociedade dos nativos é Paraíso na Terra, todo o resto instauraria a Torre de Babel na qual, consequentemente, ninguém se entende e são dependentes de quem os entenderia. Logo, vemos a questão do não nativo perpassando os domínios linguísticos e entrando no social, no político e, talvez, no econômico.

De todo modo, as posições dos autores (Davies e Rajagopalan) coincidem ao mostrar que somente o nativo teria as competências absolutas em sua língua, entretanto, ambos desmitificam essa figura quando mostram a gama de implicações que a generalização na crença e na prática desse conceito trariam.

\title{
3. Metodologia
}

A metodologia para a composição do corpus teve base em entrevista estruturada, na qual perguntas abertas foram feitas e respondidas pelos participantes por mensagens de e-mail e diálogo privado (inbox) no Facebook ${ }^{3}$.

3 A influência da definição de Davies sobre o conceito de "falante nativo" foi o fator principal para a elaboração do questionário e por meio das respostas poder-se-á conferir se o mito é 
Davis (2003) discorre que o "falante nativo" pode ser definido por estas seis maneiras (Davies, 2003):

a) O falante nativo adquire a língua materna na infância,

b) O falante nativo tem intuições (em termos de aceitação e produtividade) sobre sua gramática idioletal.

c) O falante nativo tem intuições sobre as características da gramática da linguagem padrão que são distintas de gramática idioletal

d) $\mathrm{O}$ falante nativo tem uma capacidade única de produzir discurso espontâneo e fluente, em ambos a produção e compreensão da língua materna apresenta uma ampla gama de competência comunicativa,

e) O falante nativo tem uma capacidade única de escrever de forma criativa (e isso inclui, é claro, a literatura em todos os níveis)

f) "O falante nativo tem uma capacidade única de interpretar e traduzir para a língua materna da qual é um falante."

Tendo como base as condições apresentadas pelo autor, na entrevista foram realizadas as seguintes perguntas:

1) Sua convivência com falantes nativos faz com que você concorde com as afirmações do autor?

2) Como foi aprender a língua em contato com os nativos?

3) Como você vê/avalia o curso que anuncia "inglês com falantes nativos"?

4) Você consideraria a formação pedagógica (ou ausência dela) na hora de se matricular /matricular seus filhos para essas aulas com falante nativo?

Ficou previamente esclarecido aos participantes que a pesquisa teve a finalidade de compor trabalho de final de semestre para disciplina cursada em doutorado em Linguística Aplicada e Estudos de Linguagem na PUC-SP, que a participação seria voluntária e que nenhum dos participantes seria identificado. Ficou também acordado que o fato de responder seria entendido por ambos (pesquisadora e pesquisado) concordância na participação e que a desistência seria livre e assegurada.

Os participantes da pesquisa são brasileiros que foram estudar inglês nos EUA e na Inglaterra. A fim de preservar suas identidades, eles serão aqui referidos por suas profissões na análise das respostas; o grupo de participantes consiste em: Professor (solteiro, 34 anos, residente em), Jornalista (casada, 50 anos) Psicóloga (solteira, 35 anos),

confirmado ou refutado pelos pesquisados. Foi mostrada a definição dada por Davies aos entrevistados. 
Engenheira (casada, 34 anos) e Turista (50 anos, casada). Com exceção de Turista, todos têm curso superior; Professor tem pós-graduação no Ensino de Língua Inglesa e Engenheira, faz mestrado (UNICAMP-SP). Todos pertencem ao círculo de amizades desta pesquisadora e foram escolhidos por terem vivência e estudo de língua inglesa no exterior.

\section{Análise das Respostas ${ }^{4}$}

Pergunta um: Sua convivência com falantes nativos faz com que você concorde com as afirmações do autor?

Engenheira: Na verdade não: eu sou falante nativa na minha língua e não me encaixo na definição do autor. Da mesma forma que vários dos falantes nativos de língua inglesa que conheci também não se encaixavam.

Jornalista: Inglês como qualquer outro idioma, foram criados para os humanos se comunicarem. Havendo comunicação e compreensão, onde a mensagem é recebida e interpretada, não importa o sotaque ou coisa do tipo. Mesmo porque, nativos também tem sotaques. Um americano de Pittsburgh com um do Texas tem uma linguagem própria. A partir do momento que nascemos nossa língua vai se formando conforme o idioma que ouvimos e iremos falar.

Professor: Sim, concordo com o autor, pois para ser proficiente em um idioma você precisa utilizar todos os recursos disponíveis nessa língua alvo, usar os repertórios de acordo com o lugar, pessoa e contexto social, além de ser compreendido claramente pelo falante nativo. Vale ressaltar que é muito importante ser comunicativo na língua materna, justamente porque ela te dá essa clareza, consciência em utilizar diversos tipos de linguagens dentro de um idioma que sofre transformações a todo momento.

Psicóloga: Definitivamente não concordo plenamente com o autor. Concordo apenas com a questão do sotaque. No mais, os falantes nativos de inglês não necessariamente têm capacidade única de escrita criativa, não conhecem 'todas' as regras gramaticais de sua língua (nem uma, em alguns casos) e não têm fluência e proficiência no próprio idioma.

\footnotetext{
${ }^{4}$ As respostas foram transcritas dos ambientes virtuais em que ocorreram. Os desvios de escrita são de responsabilidade dos entrevistados.
} 
Turista: Aqui eu vi um pouco de tudo: caipira, gíria que quando a gente ainda não aprendeu fica boiando, nossa, eu jamais pensaria em "borboletas no estômago" como soluços. Acho que só nas faculdades terá gente como o autor descreve.

Os pesquisados são unânimes em discordar do fato de que a natividade não garante excelência no falar e no escrever em língua materna. O Professor faz observações semelhantes às de Davies no sentido de adequar a linguagem aos diferentes lugares por onde circula, ou seja, observa o caráter social da linguagem.

Professor observa também o dinamismo pelo qual uma língua viva sofre transformações e que isso não depende apenas dos nativos, mas sim, de toda influência cultural, social e econômica, dos termos em inglês inseridos em outros falares devido à Internet e aos comunicadores instantâneos (quem bloga escreve no diário eletrônico blog, etc.).

Na passagem de locais e culturas em expansão, o que pertence ao círculo externo, como cultura, política e a própria linguagem influenciará a atitude do falante e isso ao longo do tempo trará mudanças à língua. Psicóloga e Turista falam de expressões idiomáticas, isso é parte das culturas locais com que tiveram contato; vemos então por meio das respostas, que para ser fluente, criativo e culto em uma língua é preciso mais que ser apenas falante nativo dela.

Pergunta dois: Como foi aprender a língua em contato com os nativos?

Engenheira: Acho que a grande vantagem foi aprender a língua com falantes nativos que não falavam a minha língua. Isso me forçou a usar a criatividade para compensar a falta de conhecimento da língua inglesa.

Professor: Importante, pois consegui otimizar o tempo da aprendizagem em relação aos cursos presentes aqui no Brasil, apesar de terem me dado certa base, porém não o suficiente para alcançar a proficiência, devido a artificialidade do contexto de sala de aula e laboratório de línguas, consegui realmente utilizar o idioma alvo quando estava inserido em situações reais e significativas pra mim, além de melhor compreender o uso de expressões, contexto social e cultural, era como falar para sobreviver, uma necessidade.

Jornalista: A partir do momento que nascemos nossa língua vai se formando conforme o idioma que ouvimos e iremos falar. Então, mesmo que um americano tente falar português, será muito difícil ele falar como um brasileiro. E vice-versa. Inglês deve-se se aprender a falar, mas necessariamente com um nativo? Isso não passa de bobagem. 
Psicóloga: Aprender a língua em contato com os nativos foi excelente pois internalizei expressões idiomáticas cotidianas e aumentei minha fluência. $\mathrm{O}$ melhor de tudo foi a redução quase a zero da minha inibição ao me comunicar, mesmo sabendo que meu vocabulário e conhecimento da língua era menor que muitos dos nativos com quem lidei.

Turista: Difícil e vou te dizer por quê. Na sala de aula se fala inglês, daí no café, cheio de brasileiros, português, no elevador mais brasileiros, português. No subway, brasileiros falando português, pra aprender mesmo eu não poderia sair da sala de aula pra nada. Daí pra mostrar que aprendeu, o pessoal começa a imitar o sotaque do professor, comédia.

Engenheira e Turista observam que o aprendizado com nativos se dá de fato quando a convivência no curso com os falantes da língua materna não existe. Professor e Psicóloga referiram as situações reais de uso da língua, o que nas escolas de inglês aqui do Brasil nem sempre isso ocorre. Novamente o Professor refere a importância de imergir na cultura para absorvê-la e com isso melhorar a linguagem. Jornalista refere que aprender a falar é mais importante e refuta a ideia de que falar com um nativo é o mais importante no aprendizado de inglês; refere-se ainda que um Americano não falaria português como um brasileiro nativo.

Pergunta três: Como você vê/avalia o curso que anuncia "inglês com falantes nativos"?

Engenheira: Não pesaria na escolha final por um curso de inglês.

Jornalista: Aqui por exemplo, um anuncio que diz: "Speak fluent english"...não quer dizer que o cara precisa ser nativo. Ele precisa SABER se comunicar.

Professor: Há cursos com professores nativos em seu corpo docente, isso é muito bom, porém, penso que mesmo com um curso que tenha um falante nativo, o estudante precisa ter contato com esse mundo, essa cultura, aprender um idioma não é simplesmente falar, é compreender os traços culturais presentes nele, entender o cotidiano de uma determinada sociedade e, para isso acontecer, o intercâmbio faz-se necessário, digo aqui não só o intercâmbio de viagem, mas de troca mesmo, troca de saberes, ideias... Em um curso com um professor nativo, no máximo consegue fazer um intercâmbio de ideias com uma pessoa, inserido em uma sociedade você consegue trocar saberes, compartilhar ideias e entender melhor o idioma com milhares de pessoas.

Psicóloga: Aulas com nativos são boas para aprender a falar com naturalidade e fluência. Isto não é garantia de aprendizagem de regras gramaticais, mas isto pode 
ser aprendida por si só, principalmente hoje em dia com tanta informação em bons livros e através da internet.

Turista: Propaganda enganosa, curso a gente faz com professor, um falante nativo que não seja professor vai deixar de ensinar o que precisa por que nem ele conhece. Imagina intercâmbio numa casa como a do pessoal do Duck Dinasty que você gosta de assistir, $\mathrm{kkkk}^{5}$.

Os entrevistados são unânimes ao afirmar que "falante nativo" não é o mais importante para escolher um curso de inglês. Professor e Psicóloga se referem ao preparo para ensinar ter peso maior que ser nativo. Como acena a Jornalista, o SABER tem prioridade sobre o SER.

Pergunta quatro: Você consideraria a formação pedagógica (ou ausência dela) na hora de se matricular / matricular seus filhos para essas aulas com falante nativo? ${ }^{6}$

Engenheira: Com toda a certeza. A formação acadêmica e a experiência docente para mim tem importância muito maior que a nacionalidade e a língua materna do professor.

Professor: Sim, apenas falar um idioma, ser nativo dessa língua não o habilita a lecionar, pois sabemos que há diferentes públicos dentro de uma sala de aula e cabe aos docentes primeiro conhecer todos os métodos de ensino e abordagem e não escolher ou eleger o melhor, mas utilizar aquele conforme cada aluno. Em um curso de idiomas você pode se deparar com uma sala heterogênea onde há alunos que aprendam com o método direto sem tradução, com o método estímulo resposta e reforço, o sociointeracionista, o dialogista...enfim uma gama de possibilidades, para isso é preciso ter uma formação pedagógica.

Psicóloga: Não consideraria tanto a formação pedagógica se o foco fosse a conversação. Para escrita de textos e um vocabulário e gramática mais aprofundada, certamente eu requereria, no mínimo, uma formação mais aprofundada do idioma. Melhor ainda, se tiver uma formação pedagógica, para fechar com chave de ouro.

\footnotetext{
5 A sequência de consoantes " $\mathrm{K}$ " é usada em comunicadores instantâneos como sinal de riso alto (para o que também existe a sigla LOL - laughing out loud), algo que se compare com gargalhadas.

${ }^{6}$ Esta questão é do tipo "fechada", cujas respostas esperadas seriam "sim" ou "não". Tal esclarecimento não constou da pergunta, porém, os entrevistados justificaram espontaneamente sua concordância / discordância.
} 
Turista: A formação é mais importante que o lugar onde o cara nasceu.

Nas respostas, Engenheira, Professor e Turista dão importância maior à formação pedagógica e ao preparo para lecionar; o Professor menciona que numa sala de aula o público é heterogêneo e, por isso mesmo, ensinar exige maior preparo. A Psicóloga aponta que apenas para conversação não é necessário alguém com formação pedagógica, mas que, para ensinar as regras da língua a necessidade é imperativa. A Jornalista não respondeu a esta questão.

O Professor levanta a questão de que "Em um curso de idiomas você pode se deparar com uma sala heterogênea, onde há alunos que aprendam com o método direto sem tradução, com o método estímulo resposta e reforço, o sociointeracionista, o dialogista... enfim, uma gama de possibilidades e, para isso, é preciso ter uma formação pedagógica". Sua resposta aborda concepções teórico-metodológicas que norteiam o ensino-aprendizagem de L2, bem como, as práticas pedagógicas que envolvem as habilidades comunicativas de ler-escrever-falar-ouvir e desenvolvem tais habilidades na aprendizagem da língua inglesa, para além da abordagem tradicional da gramática, conforme preceitua Widdowson (1978).

Em sua "abordagem comunicativa" Widdowson distingue o usage (emprego) de use (uso) da língua, estando o primeiro relacionado ao conhecimento de regras gramaticais e habilidades de formular frases e períodos corretamente; o segundo, relaciona-se ao entendimento de tais frases ou fragmento delas no contexto da comunicação normal. Nessa visão, é dever do professor ter ambos conhecimentos pois, usage não habilita o use, mas ter use facilitará o aprendizado de usage. Para o autor, cabe ao professor motivar e facilitar a aprendizagem e conscientizar o aluno acerca de suas experiências linguísticas e comunicativas e é justamente essa gama de habilidades exigidas do professor que o Professor entrevistado condensa ao falar da necessária "formação pedagógica", ampliando-a em use e usage.

A opinião da Psicóloga acerca da formação pedagógica do professor de L2 vai ao encontro da teoria de Widdowson no que tange ao use prévio a facilitar o usage: "Não consideraria tanto a formação pedagógica se o foco fosse a conversação: aqui estamos no nível do usei e em "Para escrita de textos e um vocabulário e gramática mais aprofundada, certamente eu requereria, no mínimo, uma formação mais aprofundada do idioma”, temos nesta fala, praticamente a descrição do usage. A Jornalista teceu comentários que esta pesquisadora considerou relevantes e, portanto, foram transcritos para o final desta análise:

"Os indianos e os africanos que chegam aqui falam inglês perfeitamente por ser matéria obrigatória de escola desde o primário. Falam inglês com sotaque, mas falam. Então nosso amigo (Davies - inserção minha) tem e não razão quando se diz: "Inglês com proficiência". Somente NATIVOS ou pessoas que tiveram uma dedicação de pequeno no 
convívio americano, poderia ter essa característica, O resto SEMPRE será falante de inglês."

A entrevistada refere-se aos imigrantes e à disciplina obrigatória, mas não se refere, especificamente, aos que chegam em idade de alfabetização. Acena ainda que somente nativos e pessoas que foram educadas com americanos teriam proficiência. Não é o que Davies argumenta. A entrevistada ainda faz afirmação excludente quando diz que quem não é educado com americanos desde pequeno será "o resto / falante de inglês". Os falantes de inglês não nativos são, de modo excludente, chamados de "Englishes". São pessoas que querem se comunicar com qualquer falante de inglês no mundo, nativo ou não, querem interagir e ser hábeis nessa interação e isso reafirma a necessidade do uso da LI com contornos locais e globais, situação linguageira a partir da qual surge o inglês com sotaque como os dos indianos e africanos, segundo alegação da entrevistada. Considero relevante trazer para esta parte da análise das entrevistas a citação de Kachru:

"Que o inglês foi (tem sido) nativizado é certamente uma verdade; mas que "esses Englishes" têm, portanto, tornando-se funcionalmente "quase ininteligível entre si" é certamente duvidoso [...]. Em termos de usos funcionais e pragmáticos da língua inglesa, o que realmente acontece é que o inglês é usado efetivamente para "pensar de forma global," e usado, por escolha, "para viver localmente" - assim estabelecendo uma ligação entre as duas identidades - global e local." (KACHRU, 2006b, p. 452)

$\mathrm{O}$ entrevistado Professor referiu na maioria de suas respostas à necessidade de saber como falar nos diferentes ambientes sociais nos quais circulamos. Os Englishes usam a LI de duas formas: "local" para a comunicação entre amigos, familiares e informalmente no trabalho, "global" no em âmbito internacional, nas relações formais de trabalho, situações diplomáticas e mesmo entre amigos nessas situações formais. Englishes e nativos: ambos fazem uso da LI nas mesmas situações que as descritas por Kachru. Ainda sobre a referência do Professor, Smith (2006) mostra os níveis de inteligibilidade para além da simples comunicação formal, informal e da formação pedagógica:

1 inteligibilidade: reconhecimento de palavras/sentenças; 2 compreensão: significado de palavras/sentenças (força locucionária); 3 interpretação: significado por trás das palavras / sentenças (força ilocucionária)14. (SMITH; NELSON, 2006, p. 429)

Portanto, não é uma questão apenas do léxico armazenado pelo nativo ou pelo fluente não nativo, é uma questão mais profunda de inserção de e na cultura cujo idioma inglês representa a ponto de compreender o dito e a mensagem subliminar que, muitas vezes, denominamos de dito oculto. 


\section{Conclusões Finais}

Em matéria de ensino de língua estrangeira, tal concepção do nativo, marcada por um grau de veneração desmedida, só deu ampla vazão ideologia neocolonialista que sempre pautou o empreendimento. O que se viu foi uma verdadeira 'apoteose do nativo (RAJAGOPALAN, 2004, p.68).

A partir da pesquisa realizada com brasileiros que optaram por aprender/aperfeiçoar seus conhecimentos de língua inglesa em países cujo inglês é a língua oficial, podemos perceber que a construção da identidade do "professor nativo" não é o requisito primeiro para a escolha de estudar fora do Brasil. Há unanimidade dos entrevistados ao afirmar que o profundo conhecimento do inglês formal é tão necessário quanto o a fluência de conversação; que a imersão na cultura inglesa e americana também são também necessárias à aquisição da fluência linguística, pois existem também os regionalismos, expressões idiomáticas e ditos populares ${ }^{7}$. As respostas apontam para a mesma direção das conclusões de Davies e Rajagopalan de que ser nativo em um idioma não é fator decisivo para que esse falante possua domínio da norma culta, fluência e proficiência desse idioma; nas respostas analisadas constatou-se que americanos e ingleses também falam errado, podem escrever mal e só chegarão aos níveis de competência absoluta por meio de muito estudo, assim como os brasileiros que estudam inglês com professor nativo.

Inferimos que a fluência está para além da coleção de itens lexicais armazenados e a capacidade de usá-los em situações formais e informais: o preparo do nativo (ou não nativo) de preparar o alunado (que muitas vezes pode ser heterogêneo, conforme referiu a Professora) incide nas competências e habilidades de desenvolver no aluno as habilidades comunicativas, igualmente para além de apenas acumular léxico e decorar normas sintáticas; espera-se desenvolvimento do ler, escrever, ouvir e falar inglês.

A presença do "mito de falante nativo" aparentemente se prende mais a estratégias comerciais que a excelência no ensino-aprendizagem de L2 uma vez que, satisfazendose as condições elencadas a partir das leituras de Davies, um não nativo pode ser linguística e pedagogicamente mais capacitado que um nativo com baixa escolaridade; a natividade do falante é considerada menos relevante, para o grupo de entrevistados, em comparação ao preparo do professor de L2 para o ensino da língua culta ensinada com base no conhecimento gramatical e léxico mais formal. $\mathrm{O}$ falante nativo apenas ajuda na fluência da conversação diária e informal.

A resposta à pergunta-título deste estudo pode ser respondida de duas maneiras: positivamente, se a necessidade de aprendizado se prende apenas ao nível informal e

\footnotetext{
${ }^{7}$ A exemplo de to have butterflies in the stomach (ter borboletas no estômago) para referir crises de soluço,
} 
conversacional de L2 e, negativamente, caso a necessidade de aprendizado seja o de aprender e alcançar um nível conversacional que possibilite a comunicação mais formal com escrita e diálogo lexicalmente rebuscados e gramaticalmente corretos. Retomando Widdowson, do uso se acederá ao emprego e, para tanto, o nativo deverá ser capacitado a ensinar o emprego da língua.

\section{Referências Bibliográficas}

COOK, V. J. 1999. Going beyond the native speaker in language teaching. TESOL Quarterly, v. 33, n. 2, p. 185-209.

DAVIES. A. 1991. The native speaker in applied linguistics. Edinburgh, Edinburgh University Press.

Matters,

2003. The native speaker: myth and reality. Clevedon: Multilingual

, 2004. The Native Speaker in Applied Lingusticis. In DAVIES, A;

ELDER, C (eds) The Handbook of Applied Linguistics. Blackwell, 2004.

PENNYCOOK, A. 1994. The cultural politics of English as an international language.

London, Longman, 365 p.

RAJAGOPALAN, K. 1997.Linguistics and the myth of nativity: comments on the controversy over "new/non-native Englishes. Journal of Pragmatics, v. 27, p. 225-231.

.2002. O conceito de identidade em linguística: é chegada a hora para uma reconsideração radical? In: I. SIGNORINI (Org.). Língua(gem) e identidade: elementos para uma discussão no campo aplicado. Campinas, São Paulo: Mercado de Letras, p. 21-45.

ética. São Paulo: Parábola Editorial.

2003. Por uma linguística crítica: linguagem, identidade e a questão . 2004a. Línguas Nacionais como Bandeiras Patrióticas, ou a linguística que nos deixou na mão. In: F. L. R. SILVA, K (Org.) A Linguística que nos faz falhar: Investigação Critica. Parabola Editorial, São Paulo, SP pgs. 11-37.

. 2004b. The concept of "World English" and its implications for ELT. ELT Journal, v. 58, n. 2, p. 111-117.

SMITH, L. E.; NELSON, C. L. 2006. World Englishes and issues of intelligibility. In: b. Kachru et al. (org.) The handbook of World Englishes. Oxford: Blackwell Publishing, p. 428-445.

SOUTO FRANCO M. M. \& ALMEIDA FILHO, J. C., 2009 O conceito de competência comunicativa em retrospectivas e perspectiva, Revista Desempenho, v. 11 p.6.

WIDDOWSON, H. G. Teaching Language as communication. Oxford: Oxford University Press, 1978. 
Rosemeyre Moraes de OLIVEIRA is graduated in Language Education from Universidade de São Marcos. She holds a Master and Doctorate degree in Applied Linguistics from the Pontifical Catholic University of São Paulo (PUC-SP). She is an Educator member at Aldeia de Carapicuiba and participates in the Research Group ILCAE-CNPQ (Linguistic Inclusion in Scenarios of Educational Activities). She also works for the São Paulo state public schools network.E-mail: rose.moraes@gmail.com 